\title{
Dermatoglyphic Patterns and Periodontal Diseases
}

\author{
Dr. Gargi Chatterjee, ${ }^{1}$ Dr. Balaji Manohar, ${ }^{1}$ Dr. Neema Shetty, ${ }^{1}$ Dr. Aditi Mathur, ${ }^{1}$ Dr. Barkha Makhijani ${ }^{1}$ \\ ${ }^{1}$ Department of Periodontics, Pacific Dental College and Hospital, Debari, Udaipur, India.
}

\begin{abstract}
Background: Periodontal disease is initiated by bacterial accumulation but some risk factors like genetics also can be responsible for disease progression. Genetic determinants that exist could be suggestive of specific dermatoglyphic patterns for periodontitis. Hence, the present study was an attempt to find if there is any correlation between fingerprint patterns and periodontal diseases.

Aim: To compare the fingerprint patterns in generalised chronic periodontitis and chronic generalised gingivitis subjects.

Materials and methods: 800 subjects were included in the study. 437 subjects were diagnosed with generalised chronic periodontitis and 363 subjects were diagnosed with chronic generalised gingivitis. Fingerprint patterns were recorded and were analysed manually with illuminated $6 \mathrm{X}$ high powered magnifying glass. SPSS software was used for statistical analysis.

Results: An increased frequency of radial loop pattern (39.01\%) was found in chronic generalised gingivitis subjects, whereas; in generalised chronic periodontitis subjects higher frequency of ulnar loop (37.53\%) and central pocket whorl pattern (36.16\%) was observed.

Conclusion: Dermatoglyphics could be used together with the other diagnostic aids for prediction of periodontal diseases.

Keywords: Dermatoglyphics; fingerprint patterns; genetics; periodontitis.
\end{abstract}

\section{INTRODUCTION}

Dermatoglyphics is a special branch of scientific studies which deals with the skin ridge patterns on the fingers, toes, palms of hands and soles of feet. The word dermatoglyphics originated from two Greek words: derma meaning skin and glyphe meaning carve and it was coined by Harold Cummins in 1926. The finger and palm prints start to form during the 6 th to 7 th week of embryonic life and is completed after 10 to 20 weeks of gestation. These dermal ridge patterns remain unchanged throughout the life. ${ }^{1,2}$ As the type of finger print is a genetically unique characteristics of each individual, it can be considered as a beneficial tool for prediction of any congenital, intrauterine anomalies or other diseases which are aetiologically influenced by genetic alterations. ${ }^{3}$ It is now well established that certain specific dermatoglyphic patterns are significantly observed in some diseases which purely are genetic disorders, such as Down's syndrome, Turner's syndrome, Klinefelter syndrome, Edwards

\section{Correspondence:}

Dr. Gargi Chatterjee

Department of Periodontics,

Pacific Dental College and Hospital, Debari, Udaipur, India. email:gargi.chat@rediffmail.com

\section{Citation}

Chatterjee G, Manohar B, Shetty N, Mathur A, Makhijani B. Dermatoglyphic patterns and periodontal diseases. J Nepal Soc Perio Oral Implantol. 2017;1(2):55-9. syndrome etc..$^{4-7}$ Variations in dermatoglyphic patterns are also noticed in neurological diseases like Alzheimer's disease, schizophrenia, cerebral palsy, neurofibromatosis, epilepsy; heart disease like congenital heart disease, rheumatoid heart disease, coronary heart disease. Some unique fingerprint and ridge patterns are frequently seen in patients suffering from diabetes mellitus, cervical cancer, leprosy, essential hypertension, bronchial asthma, rheumatoid arthritis, tuberculosis, breast carcinoma and sickle cell anemia. ${ }^{8-23}$

In recent times, recognition of irregular fingerprint patterns has become a point of interest in the field of dentistry. The work conducted by various authors showed there are some significant dermatoglyphic peculiarities in persons with dental problems such as periodontitis, ${ }^{24}$ dental caries, ${ }^{25}$ cleft lip and cleft palate, ${ }^{23}$ oral submucous fibrosis, bruxism, oral squamous cell carcinoma, oral leukoplakia and taurodontism. ${ }^{26-30}$

There are three basic types of finger print patterns a) Arches b) Loops and c) Whorls. The arch pattern is subdivided into two types: plain arch and tented arch. Loop pattern is subdivided into ulnar loop and radial loop whereas; subtypes of whorl patterns include double loop whorl, plain whorl, central pocket whorl and accidental whorl (Figure 1). ${ }^{31}$

The most prevalent form of periodontitis, the chronic periodontitis is a slowly progressing inflammatory 


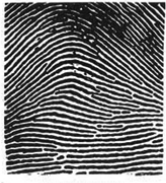

Plain Arch

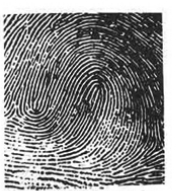

Double Loop Whorl

Figure 1: Fingerprint patterns and classifications.
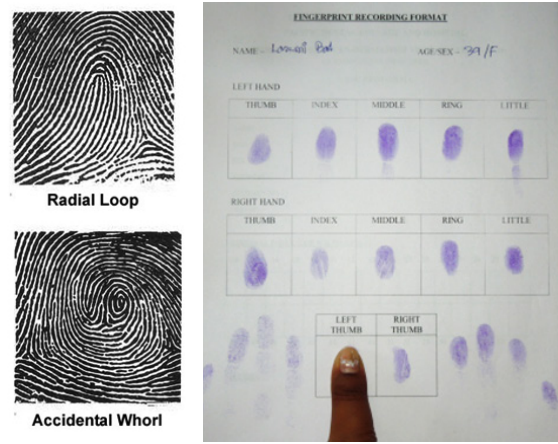

Figure 2: Fingerprint recording format and analysis.

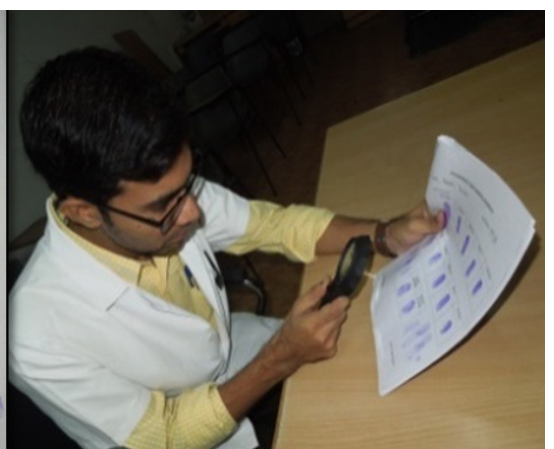

disease involving the supporting tissues of the teeth causing progressive attachment loss and bone loss. Although, the aetiopathology of this disease is mostly influenced by microbiological factors, systemic diseases and immunological factors, genetic variations also play an important role in the aetiopathogenesis. ${ }^{32}$ Role of host genes in the aetiopathogenesis of periodontal diseases have been useful in developing screening tools for identifying patients who are likely to develop disease.

With this background, the present study was conducted to find the possible link between specific finger print patterns and periodontal diseases. The present study aimed to compare the fingerprint patterns in generalised chronic periodontitis and chronic generalised gingivitis patients.

\section{MATERIALS AND METHODS}

Subjects for the study were selected from the regular outpatient Department of Periodontology. The subjects were explained about the study and were included after obtaining an informed consent. 800 subjects were enrolled in the study. Clinical evaluation was done, Gingival index (Loe and Silness), Oral hygiene index (Greene and Vermillion) and probing pocket depth were measured. Subjects with pocket depth $\geq 5 \mathrm{~mm}$ in more than $30 \%$ sites were diagnosed as suffering from generalised chronic periodontitis. Among the 800 subjects, 437 subjects were diagnosed with generalised chronic periodontitis (Group I) and 363 subjects were diagnosed with chronic generalised gingivitis (Group II). Fingerprint patterns of all subjects were recorded on a prepared recording format using blue ink pad. Fingerprint pattern analysis was done manually using an illuminated $6 \mathrm{X}$ high powered magnifying glass (Figure 2). The obtained data were subjected to statistical analysis. SPSS software was used for statistical analysis. For qualitative analysis, Chi Square test was used.

\section{RESULTS}

Of the 800 subjects enrolled in the study, 437 (54.62\%) were diagnosed with generalised chronic periodontitis and were placed in group I.
Of these 212 (48.51\%) were males and 225 (51.48\%) were females. The most common pattern of fingerprint observed was the ulnar loop pattern which was exhibited by 164 (37.53\%) subjects. This pattern was exhibited by 82 (39.42\%) males and 82 (35.81\%) females. The second most common fingerprint pattern observed in group I was Central pocket whorl which was seen in 158 (36.16\%) subjects. 81 (38.46\%) males and 77 (35.37\%) females had this type of fingerprint pattern. The least common type of fingerprint was the plain arch type of pattern seen in 6 (1.37\%) of subjects and was seen to be present only amongst the male subjects (2.88\%). None of the females exhibited this pattern. The second least common fingerprint type was seen to be the double loop whorl in 7 (1.60\%) subjects and was seen to be present only in the female subjects (3.06\%). None of the male demonstrated this pattern of fingerprint type. Plain whorl (39) followed by accident whorl (37), tented arch (15) and radial loop (11) were the other patterns of fingerprints seen in the order of occurrence.

363 (45.37\%) subjects were diagnosed with chronic generalised gingivitis and were placed in group II. Of these 156 (42.96\%) were males and 207 (57.02\%) were females. The most common fingerprint pattern observed was the radial loop which was exhibited by 142 (39.01\%) subjects. 58 (36.13\%) males and 84 (40.38\%) females exhibited this pattern of fingerprint. The second most common pattern of fingerprint observed in group II was double loop whorl pattern which was seen in 52 subjects (14.29\%). 17 (10.97\%) males and 35 (16.83\%) females had this type of fingerprint pattern. The least common type of fingerprint was the plain arch type of pattern seen in 12 (3.30\%) subjects and was seen to be present in 5 (3.23\%) males and 7 (3.37\%) females. The second least common fingerprint type was seen to be the central pocket whorl in 16 (4.40\%) subjects and was seen to be present in 10 (4.52\%) males and 6 (2.88\%) females.

Accident whorl (43) followed by tented arch (35), ulnar loop (32), plain whorl (31) were the other patterns of fingerprints seen in the order of occurrence (Table 1, Figure 3, 4, 5). 
Table 1: Dermatoglyphic pattern in generalised chronic periodontitis (Group I) and chronic generalised gingivitis (Group II) subjects.

\begin{tabular}{|c|c|c|c|c|c|c|c|}
\hline \multirow{2}{*}{\multicolumn{2}{|c|}{ Fingerprint patterns }} & \multicolumn{3}{|c|}{ Group I } & \multicolumn{3}{|c|}{ Group II } \\
\hline & & \multirow{2}{*}{$\begin{array}{c}\text { Male } \\
06\end{array}$} & \multirow{2}{*}{$\begin{array}{c}\text { Female } \\
00\end{array}$} & \multirow{2}{*}{$\begin{array}{c}\text { Total } \\
06\end{array}$} & \multirow{2}{*}{\begin{tabular}{|lr} 
& Male \\
05 &
\end{tabular}} & \multirow{2}{*}{$\begin{array}{c}\text { Female } \\
07\end{array}$} & \multirow{2}{*}{\begin{tabular}{|l} 
\\
12
\end{tabular}} \\
\hline $\mathrm{pA}$ & No & & & & & & \\
\hline PA & $\%$ & $02.88 \%$ & $00.00 \%$ & $01.37 \%$ & $03.23 \%$ & $03.37 \%$ & 03.30\% \\
\hline \multirow{2}{*}{$\mathrm{TA}$} & No & 05 & 10 & 15 & 05 & 30 & 35 \\
\hline & $\%$ & $02.40 \%$ & $04.37 \%$ & 03.43\% & $03.23 \%$ & $14.42 \%$ & 09.62\% \\
\hline \multirow{2}{*}{$\mathrm{UL}$} & No & 82 & 82 & 164 & 19 & 13 & 32 \\
\hline & $\%$ & $39.42 \%$ & $35.81 \%$ & $37.53 \%$ & $12.26 \%$ & $06.25 \%$ & $08.79 \%$ \\
\hline \multirow{2}{*}{ RL } & No & 06 & 05 & 11 & 58 & 84 & 142 \\
\hline & $\%$ & 03.85\% & $02.18 \%$ & $02.52 \%$ & $36.13 \%$ & $40.38 \%$ & $39.01 \%$ \\
\hline \multirow{2}{*}{ DLW } & No & 00 & 07 & 07 & 17 & 35 & 52 \\
\hline & $\%$ & $00.00 \%$ & 03.06\% & $01.60 \%$ & $10.97 \%$ & $16.83 \%$ & $14.29 \%$ \\
\hline \multirow{2}{*}{ PW } & No & 13 & 26 & 39 & 20 & 11 & 31 \\
\hline & $\%$ & $05.29 \%$ & $11.35 \%$ & 08.92\% & $15.48 \%$ & $04.33 \%$ & $08.52 \%$ \\
\hline \multirow{2}{*}{ CPW } & No & 81 & 77 & 158 & 10 & 06 & 16 \\
\hline & $\%$ & $38.46 \%$ & $35.37 \%$ & $36.16 \%$ & $04.52 \%$ & $02.88 \%$ & $04.40 \%$ \\
\hline \multirow{2}{*}{$\mathrm{AW}$} & No & 19 & 18 & 37 & 22 & 21 & 43 \\
\hline & & $07.69 \%$ & $07.86 \%$ & $08.47 \%$ & $14.19 \%$ & $11.54 \%$ & $11.85 \%$ \\
\hline
\end{tabular}

Figure 3: Fingerprint patterns.

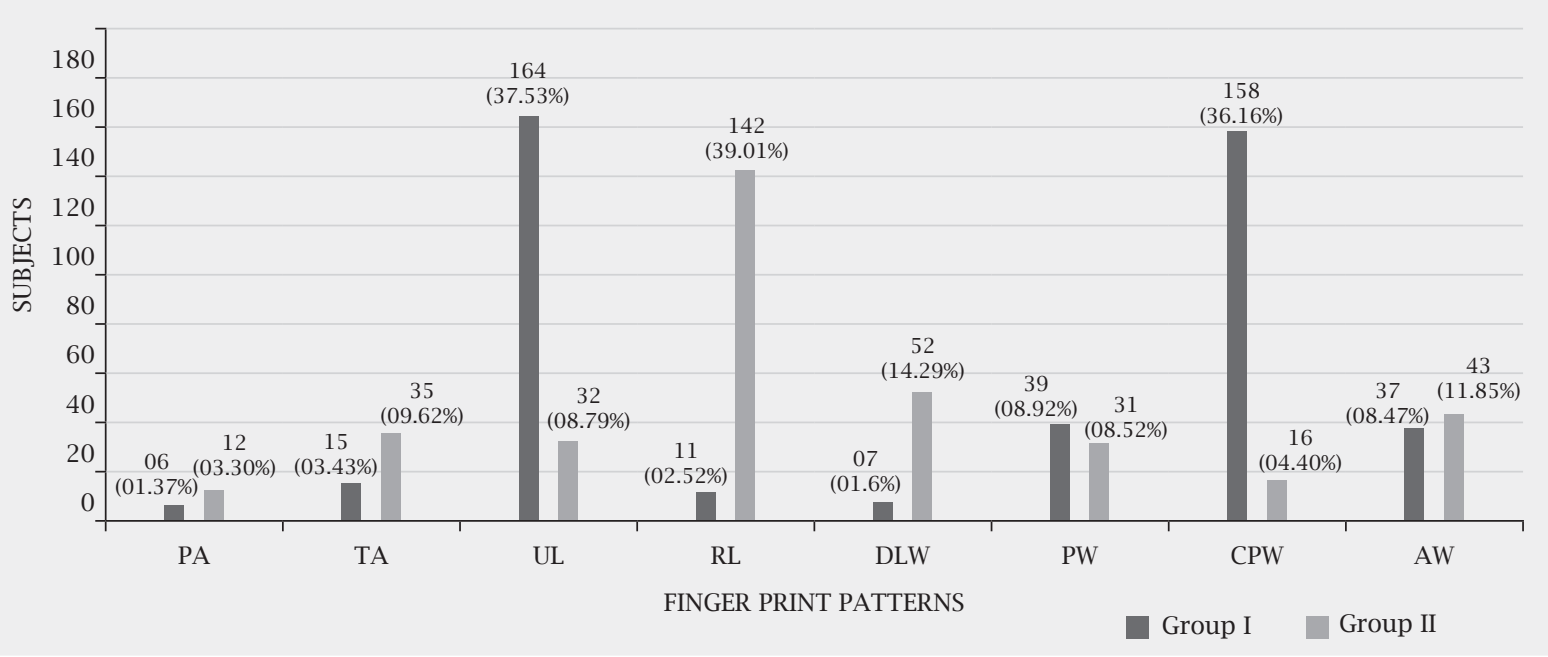

Figure 4: Fingerprint patterns in subjects with generalised chronic periodontitis.

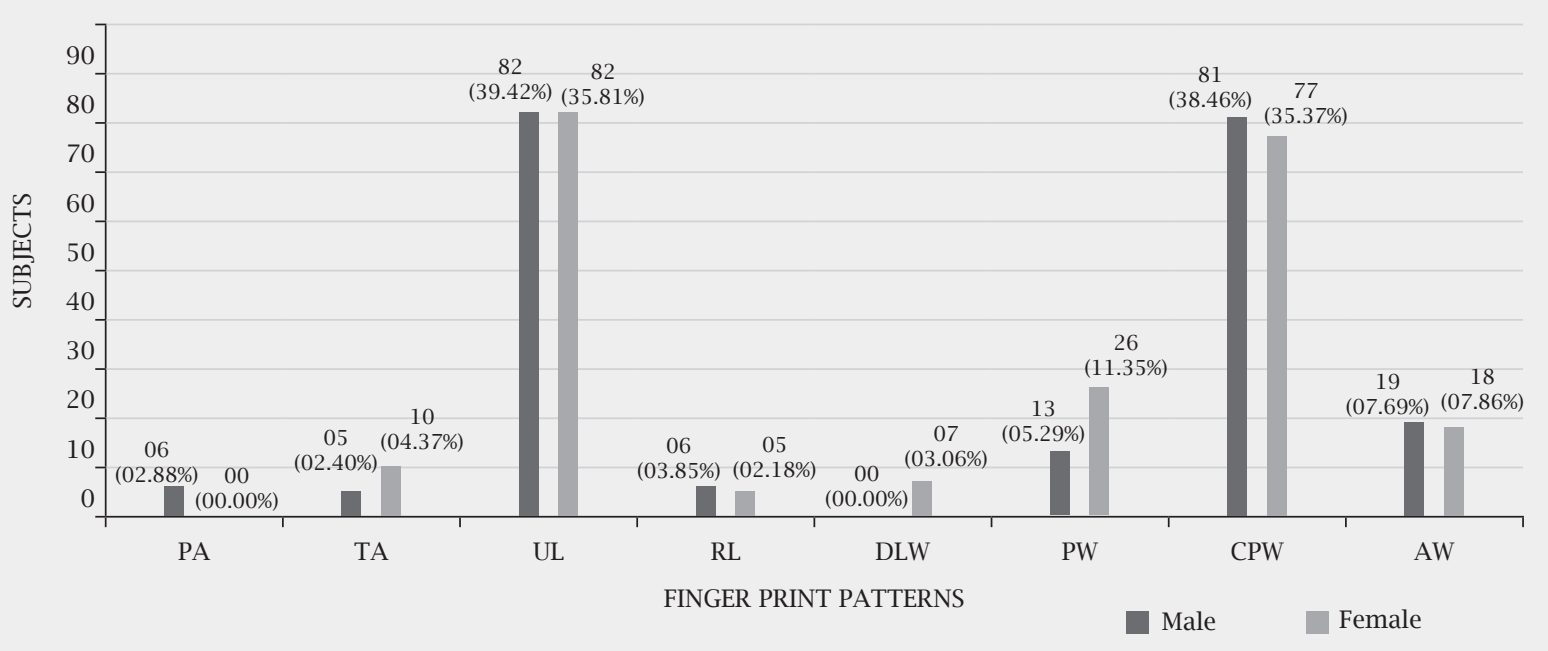


Figure 5: Fingerprint patterns in subjects with chronic generalised gingivitis.

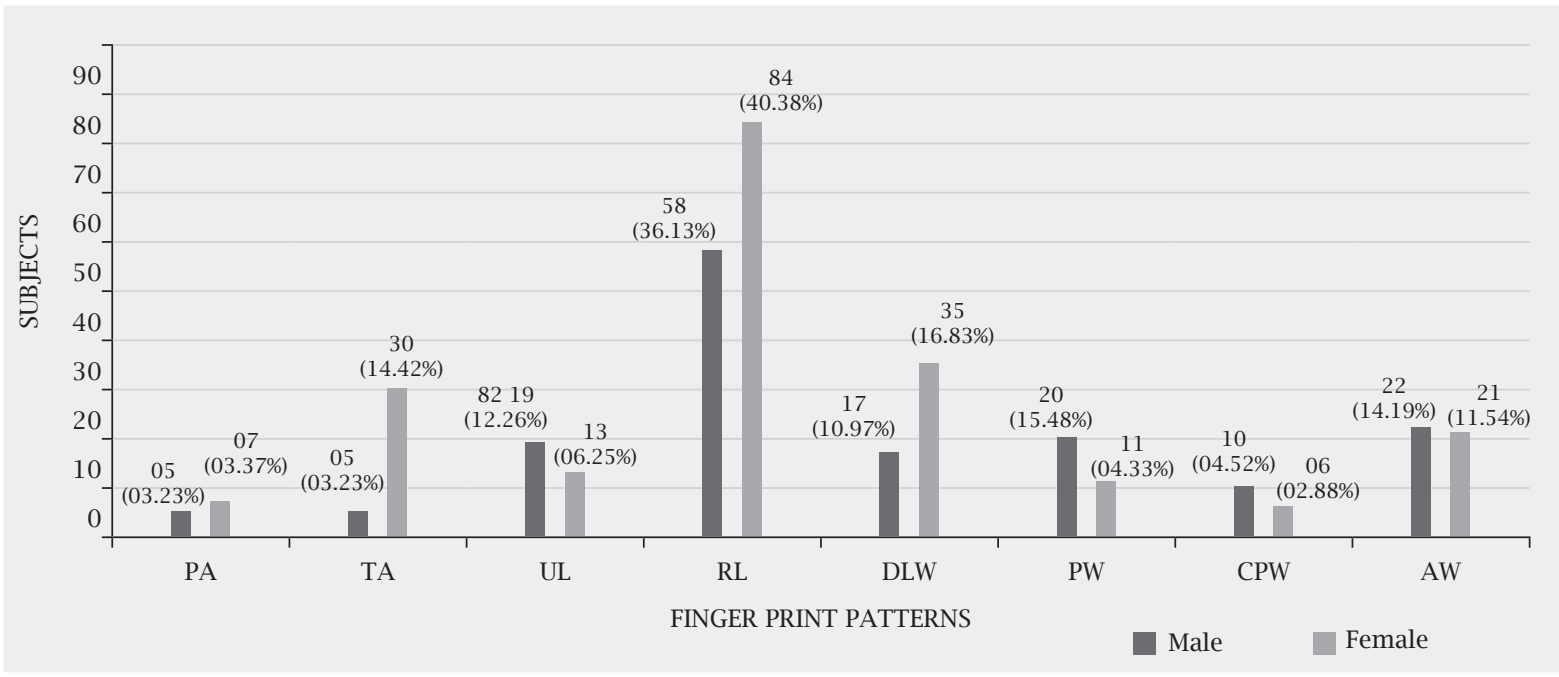

\section{DISCUSSION}

Dermatoglyphic pattern analysis have been carried out as an advantageous tool in various research aspect of biology, medicine and genetics and has proven to be an effective key to predict occurrences and risks for biomedical events.

Yilmaz S et al. ${ }^{33}$ conducted a study with 36 early onset periodontitis, 20 adult periodontitis patients and 20 periodontally healthy individuals. The study emphasized the diagnostic value of the quantitative and qualitative characteristics of patterns of ridged skin, and the effect of heredity on periodontal diseases were discussed. Shyamala $\mathrm{K}$ et $\mathrm{al}^{34}$ carried out a study to determine the specific dermatoglyphics pattern and establish the prevalence of a specific fingertip pattern that can act as a susceptible factor for aggressive periodontitis. The study included 30 patients, aged between 20 to 35 year, diagnosed with and treated for aggressive periodontitis (Study group) and 30 periodontally healthy individuals (Control group). Fingerprint patterns of all subjects were recorded for analysis and results showed there was increased frequency (60\%) of double loop whorl on left and right thumb of study group and presence of single loop whorl (60\%) on left ring fingers of study group.

Devishree et al. $^{35}$ compared the palmar dermatoglyphic features in aggressive periodontitis patients and periodontally healthy individuals. 15 patients with aggressive periodontitis and 15 periodontally healthy subjects were included and fingerprint patterns were obtained. Analysis of fingerprint patterns was done with the help of Automated Fingerprint Identification System (AFIS). Significantly higher frequency of ulnar loops was observed on all fingers of patients with aggressive periodontitis. Atasu $\mathrm{M}$ et $\mathrm{al} .^{24}$ compared the finger-tip patterns of the juvenile periodontitis patients with those of periodontally healthy individuals. They reported decreased frequencies of twinned and transversal ulnar loops on all fingers of the patients with juvenile periodontitis, a decreased frequency of double loops on all fingers and an increased frequency of radial loops on the right second digits of the patients with rapidly progressing periodontitis and the increased frequencies of concentric whorls and transversal ulnar loops on all fingers of the patients with adult periodontitis, an increased frequency of e triradii on the palms of the patients with juvenile periodontitis, the increased frequencies of IV and $\mathrm{H}$ loops and tb triradii on the palms of the patients with rapidly progressing periodontitis and an increased frequency of e triradii on the soles of the patients with juvenile periodontitis.

The present study also showed an increased frequency of ulnar loop and central pocket whorl patterns of fingerprint in both males and females with generalised chronic periodontitis. The least common type of fingerprint was the plain arch and the second least common type of fingerprint was double loop whorl patterns. The plain arch pattern was present in only male subjects whereas, double loop whorl pattern was present in only female subjects. Increased frequency of radial loop fingerprint pattern was seen to be present in both females and males with chronic generalised gingivitis (Group II). The second most common type of fingerprint pattern was double loop whorl pattern and it is present in higher frequency in females than males. The least common type of fingerprint pattern was plain arch in both males and females and the second least common type of fingerprint was central pocket whorl. The finding of increased frequency of ulnar loop pattern in generalised chronic periodontitis group is similar to the study done by Devishree et al..$^{35}$ and Atasu $\mathrm{M}$ et al. ${ }^{24}$ where significantly higher frequency of ulnar loop was observed in subjects with aggressive periodontitis and adult periodontitis respectively. 


\section{CONCLUSION}

Within the limitations of the study, it was established that certain fingerprint patterns were in greater frequency in generalised chronic periodontitis patients. Dermatoglyphics could be used as an adjunctive aid in the prediction of subjects at risk of developing periodontal diseases along with other diagnostic aids. However, further studies with larger sample size are required to arrive at a conclusive report linking dermatoglyphic patterns in periodontal diseases.

\section{REFERENCES}

1. Sharma A, Palvi, Kapoor D. Dermatoglyphics, Dentistry and Diagnosis-A Review. Baba Farid University Dental Journal. 2010;1(2):45-8.

2. Bhat GM, Mukhdoomi MA, Shah BA, Ittoo MS. Dermatoglyphics in health and disease - A review. Int J Res Med Sci. 2014;2:31-7.

3. Kiran K, Rai K, Hegde AM. Dermatoglyphics as a noninvasive diagnostic tool in predicting mental retardation. J Int Oral Health. 2010;2:95-100.

4. Rajangam S, Janakiram S, Thomas IM. Dermatoglyphics in Down’s syndrome. J Indian Med Assoc. 1995;93(1):10-3.

5. Miglinets V. Relationship between dermatoglyphic variability and finger length in genetic disorders: Down's syndrome. Genetica. 1991;27(3):541-7.

6. Reed T, Reichmann A, Palmer C. Dermatoglyphic differences between 45x and other chromosomal abnormalities of Turner's syndrome. Hum Genet. 1977;36(1):13-23.

7. Komotz Y, Yoshida O. Finger patterns and ridge counts of patients with Klinefelter's syndrome (47xxy) among the Japanese. Hum Hered. 1976;26(4):290-7.

8. Weinre H. Finger print pattern in Alzheimer's disease. Arch Neurol. 1995;42(1):50-4.

9. Gupta CM, Tutakne MA. An evaluation of palmer flexion creases and dermatoglyphics in Leprosy. Indian J Lepr. 1986;58(2):263-75.

10. Simsek S, Taskiran H, Karakaya N, Fistik T, Solak M, Cakmak EA. Dermatoglyphic analysis in children with cerebral palsy. Neurobiology (Bp). 1998;6(3):373-80.

11. Pallotta R, Carlone G, Petrucci A, Chiarelli F. Dermatoglyphics in Von Recklinghausen neurofibromatosis. Am J Med Genet. 1989;34(2):233-6.

12. Lal N, Surekha RK. A study of dermatoglyphic pattern in epileptic patients. J Anat Soc India. 2012;61(1):26-9.

13. Nair R. Dermatoglyphic diversity in congenital heart diseases. Indian J Medical Res. 1986;83:56-67.

14. Annupurna V, Ahuja YR, Reddy GD, Rao VS, Rao PN. Dermatoglyphics studies in rheumatic heart disease. Hum Hered. 1978;28:72-8.

15. Chimne HD, Ksheersagar DD. Dermatoglyphics in angiographically proven coronary artery disease. J Anat Soc India. 2012;61(2):262-8.

16. Ravendranath R, Thomas IM. Finger ridge count and finger print pattern in maturity onset diabetes mellitus. Ind J Med Sci. 1995;49:153-6.

17. Pal GP, Roufal RV, Bhagvat SS. Dermatoglyphics in carcinoma cervix. J Ant Soc India. 1985;34(3):157-61.

18. Pursani MZ, Elhence GP, Tibrewala L. Palmer dermatoglyphics in essential hypertension. Indian Heart J. 1989;41:119-22.

19. Gupta UK, Prakash S. Dermatoglyphics: a study of fingertip patterns in bronchial asthma and its genetic disposition. Kathmandu Univ Med J. 2003;1(4):267-71.

20. Ravindranath R, Shubha R, Nagesh HV. Dermatoglyphics in rheumatoid arthritis. Ind J Med Sci. 2003;57:437-41.

21. Cummins H, Midlo C. Finger prints, palms and soles: an Introduction to dermatoglyphics. New York: Dover publications; 1961.

22. Chintamani, Khandelwal R, Mittal A, Saijanani S, Tuteja A, Bansal A, Bhatnagar D, Saxena S. Qualitative and quantitative dermatoglyphic traits in patients with breast cancer: a prospective clinical study. BMC Cancer. 2007 Mar 13;7:44.

23. Balgir RS. Dermatoglyphics Nigeria: dermatoglyphic analysis of 90 cases. Afr J Biochem Res. 2007;1(4):54-9.

24. Atasu M, Kuru B, Firatli E, Meric H. Dermatoglyphic findings in periodontal diseases. Int J Anthropol. 2005;20:63-75.

25. Atasu M. Dermatoglyphic findings in dental caries: a preliminary report. J Clin Pediatr Dent. 1998;22:147-9.

26. Fulzele RR, Chimurkar VK, Rawlani SS, Sherke AR. Qualitative dermatoglyphic analysis of fingertip patterns in patients of oral submucous fibrosis. J Dent Med Sci. 2013;6:24-7.

27. Polat MH, Azak A, Evlioglu G, Malkondu OK, Atasu M. The relation of bruxism and dermatoglyphics. J Clin Pediatr Dent. 2000;24:191-4.

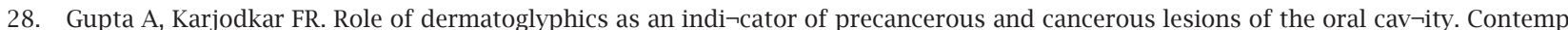
Clin Dent. 2013:4(4):448-53.

29. Venkatesh E, Bagewadi A, Keluskar V, Shetti A. Palmar dermatoglyphics in oral leukoplakia and oral squamous cell carcinoma patients. J Indian Acad Oral Med Radiol. 2008;20(3):94-9.

30. Genc A, Namdar F, Goker K, Atasu M. Taurodontism in association with supernumerary teeth. J Clin Pediatr Dent. 1999;23:151-4.

31. Federal Bureau of Investigation. The science of fingerprints - classification \& uses. 1st ed. Washington D.C., United States: Federal Bureau of Investigation; 1957.

32. Llorente MA, Griffiths GS: Periodontal status among relatives of aggressive periodontitis patients and reliability of family history report. J Clin Periodontol. 2006;33:121-5.

33. Yilmaz S, Atasu M, Kuru B. A genetic and dermatoglyphic study on periodontitis. J Marmara Univ Dent Fac. 1993;1(4):297- 306.

34. Shyamala K, Hemavathy S, Girish HC, Murgod S. Dermatoglyphis in aggressive periodontitis: A genetic analysis. Indian J Dent Sci. 2015;7(5):40-3.

35. Devishree G, Gujjari SH. Dermatoglyphic patterns and aggressive periodontal diseases - A possible link? J Med Dent Sci. 2015;14(4):6972. 